\title{
Simulation the effect of anode-cathode displacement and anode type on reinforced concrete cathodic protection using BEM
}

\author{
Syarizal Fonna ${ }^{*}$, Syifaul Huzni ${ }^{1}$, Muzaiyin Arika Putra $^{1}$, and Rudi Kurniawan ${ }^{1}$ \\ ${ }^{1}$ Syiah Kuala University, Department of Mechanical and Industrial Engineering, Jl. Tgk. Syech Abdur Rauf No. 7, Banda Aceh 23111, \\ Indonesia
}

\begin{abstract}
The aim of the study is to simulate the effect of anode-cathode displacement and anode type on the potential distribution of reinforced concrete (RC) cathodic protection (CP) system using boundary element method (BEM). For the simulation, Laplace equation was used to model the RC domain. The boundary conditions for the anode and cathode (reinforcing steel/rebar) were represented by its polarization curve. By using BEM, the electrical potential values on the whole domain should be calculated. Therefore, the effects of those parameters were studied based on the rebar electrical potential. For the study, the CP system model and geometry were obtained from a previous researcher. The BEM simulation results show that the anode-cathode displacement affects the distribution of electrical potential on the protected reinforcing steel. It was consistent with the previous research result. The results also show, as expected, that the anode type influences the electrical potential value on the rebar. Hence, those parameters should be considered in designing and/or evaluating the RC CP system.
\end{abstract}

\section{Introduction}

Corrosion is the phenomenon of metal deterioration because of its interaction with the environment. It already becomes a worldwide problem. Every year, 3$4 \%$ of the global GDP has been wasted due to corrosion [1].

The infrastructure sector is one of the sectors that impacted by corrosion. It includes reinforced concrete (RC) structures. In this sector, the losses have reached more than $70 \%$ of the total corrosion losses [2]. Furthermore, the media have reported that the corrosion on RC infrastructure has resulted in casualties. The examples are the collapse of the Silver Bridge in the United States in 1967 [3], and the collapse of a toll road bridge in Canada in 2006 [4]. Thus, it is important and necessary to perform corrosion control and monitoring of RC structures [5], and also to conduct corrosion detection [6].

Cathodic protection (CP) is one of the popular corrosion control methods. The method is also implemented on RC structures. The use of the method has been widely reported [7-9]. However, researchers and engineers still challenged in exploring the field of designing and evaluating of the protection system [10]. The effect of parameters on the CP system of the RC structure still necessary to be further understood because of might influenced the performance of the system [9].

Numerical method is one of the tools for solving various engineering problems that has progressed significantly. One of the methods is boundary element method (BEM) that has been used of the for the simulation of galvanic corrosion [11]. BEM has also been utilized to simulate $\mathrm{CP}$ systems in marine $[10,12$ 13] and underground environments [14]. The results show that the distribution of electrical potentials in the protected structures could be performed by BEM. This capability will be beneficial in both the design process and the evaluation of the $\mathrm{CP}$ system.

Previous research has conducted a simulation to study the influence of anode size and concrete conductivity to the RC CP system [10]. The influence of other parameters still needs to be understood. Therefore, this research aims to simulate a cathodic protection system on an RC structure using BEM in order to study the effect of anode-cathode displacement and anode type on the distribution of electrical potentials on the reinforcing steel.

\section{BEM formulations for RC CP}

The system of $\mathrm{CP}$ for an $\mathrm{RC}$ structure is modeled as depicted in Figure 1. The RC model consists of reinforcing steel/rebar and sacrificial anode. The rebar and the anode are electrically connected in the RC model.

For the RC model, an assumption is made that the $\mathrm{CP}$ system has no ion in-and-out. Thus, the system might be mathematically modeled by using the Laplace equation as given in Equation (1) [15-16]. The equation represents the electrical potential $(\phi)$ for the whole concrete domain $(\Omega)$.

The electrical potential $(\phi)$ and the current density $(i)$ for the whole domain of the RC model is having a

\footnotetext{
*orresponding author: syarizal.fonna@unsyiah.ac.id
} 
relationship as given in Equation (2). In this equation, $\kappa$ is the conductivity of the concrete, and $\mathbf{n}$ is the normal vector.

$$
\begin{array}{cc}
\nabla^{2} \phi=0 & \text { in } \Omega \\
\mathrm{i}=-\kappa \frac{\partial \phi}{\partial \mathbf{n}} & \left(\mathrm{A} / \mathrm{m}^{2}\right)
\end{array}
$$

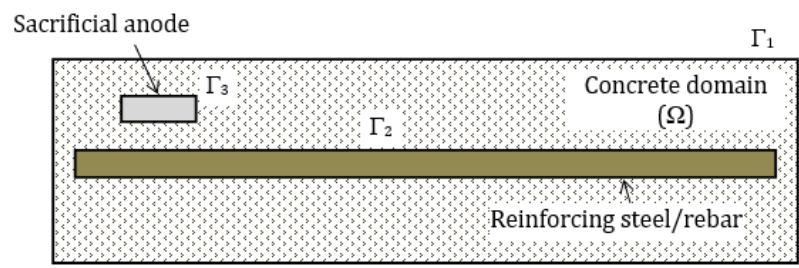

Fig. 1. RC CP system model.

Some boundary conditions (BC) of the RC model have to be known for solving Equation (1). Those boundary conditions are shown in Equation (3) - (5). For the concrete surface $\left(\Gamma_{1}\right)$, the $\mathrm{BC}$ is as given by Equation (3). The zero value of current density is as a result of the very low conductivity of the concrete.

$$
\begin{array}{lll}
i=i_{0}=0 & \left(\mathrm{~A} / \mathrm{m}^{2}\right) & \text { on } \Gamma_{1} \\
\phi=-f_{c}(i) & (\mathrm{V}) & \text { on } \Gamma_{2} \\
\phi=-f_{a}(i) & (\mathrm{V}) & \text { on } \Gamma_{3}
\end{array}
$$

Furthermore, the BC for the rebar $\left(\Gamma_{2}\right)$ and the anode $\left(\Gamma_{3}\right)$ surfaces are generated from each polarization curve. These BCs are shown in Equation (4) and Equation (5), respectively. The polarization curve represented the behavior of a metal when it is undergoing anodic or cathodic reaction and obtained from an experiment.

Boundary element method (BEM) was developed by following the procedure as given in $[11,17]$. The procedure might result in an equation as Equation (6). The full details of the $[\mathrm{H}]$ and $[\mathrm{G}]$ matrices could be found in reference [17].

$$
\kappa[H]\left\{\begin{array}{c}
\phi_{\Gamma 1} \\
-f_{c}(i) \\
-f_{a}(i)
\end{array}\right\}-[G]\left\{\begin{array}{l}
i_{0} \\
i_{c} \\
i_{a}
\end{array}\right\}=0
$$

Thus, Equation (1) can be solved by using BEM with $\mathrm{BC}$ in Equation (3) - (5). All the electrical potential and current density values for the whole $\mathrm{RC}$ domain can be determined by executing BEM. For the evaluation of CP of $\mathrm{RC}$, the electrical potential value on the rebar surface will be utilized.

\section{Case study}

A case study had been selected for this study. The case study was derived from the works of Dodds et al. [18]. Figure 2 shows the $\mathrm{CP}$ system for $\mathrm{RC}$ that is simulated in this study. The geometry of RC model was $(80 \times 10 \times$ 10) $\mathrm{cm}$. A rebar was cast in the concrete that has a size of $(61 \times \Phi 2.5) \mathrm{cm}$. The positioning of rebar and anode in the concrete are as shown in the model of Figure 2. The anode used for the simulation of cathodic protection was having the geometry of $(6.5 \times \Phi 3) \mathrm{cm}$.
The development of geometry and meshing (using triangle element) of concrete, rebar, and anode were using Salome software. Total element for the whole component was 1376 element, i.e. 852, 498, and 26 elements for concrete, rebar, and anode, respectively.

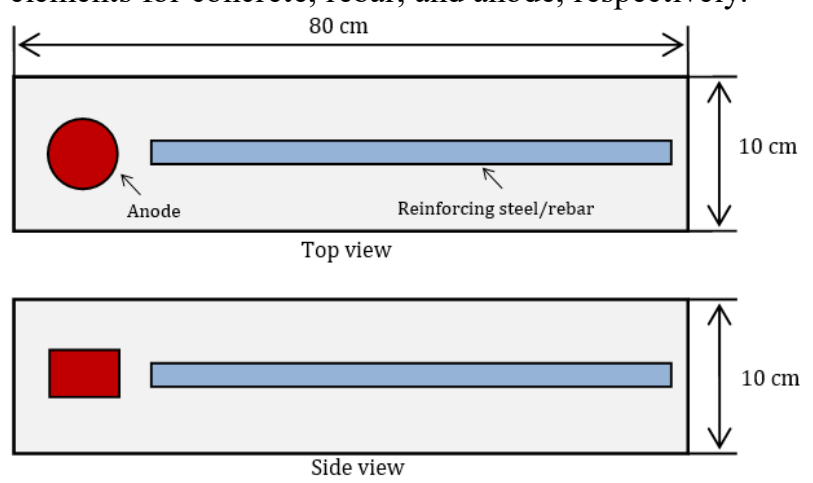

Fig. 2. The geometry of RC for simulation based on the work of Dodds et al. [18].

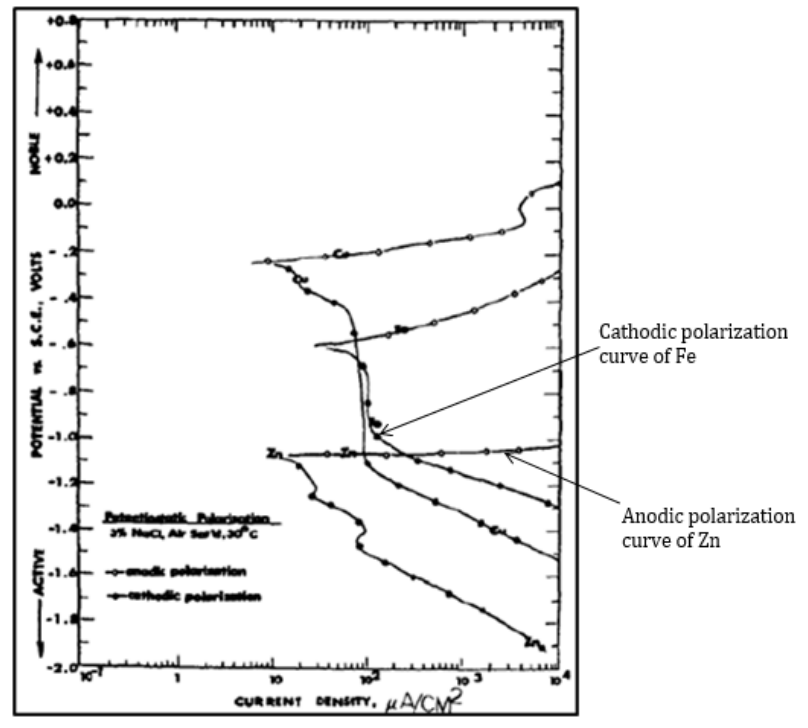

Fig. 3. Polarization curves of Fe and $\mathrm{Zn}$ [19].

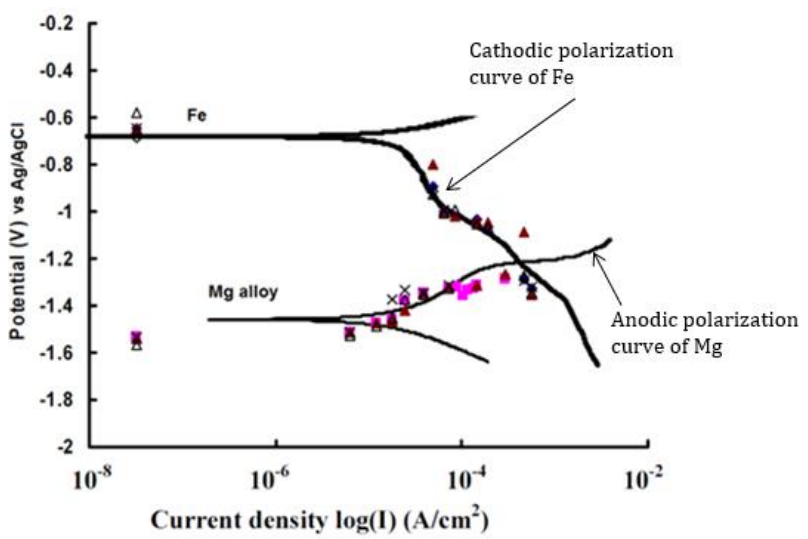

Fig. 4. Polarization curves of Fe and $\mathrm{Mg}$ [20].

The first simulation was to study the effect anodecathode displacement to the distribution of electrical potential on rebar surface, i.e. at the nearest and furthest point from the anode. For simulation purposes, the $\mathrm{Zn}$ 
anode was used, and the concrete conductivity value was $0.007 \Omega-{ }^{1} \mathrm{~m}^{-1}$.

The $\mathrm{BC}$ for the $\mathrm{Zn}$ anode and rebar were derived from [19] as shown in Figure 3. The BC for the $\mathrm{Zn}$ anode was the anodic polarization curve, whereas for the rebar was the cathodic polarization curve as shown in the figure. The anode-cathode displacements used for this study were $5 \mathrm{~cm} ; 10 \mathrm{~cm}$; and $20 \mathrm{~cm}$.

Then, the second simulation was to study the effect of the anode type on the electrical potential distribution of the rebar. In the study, the $\mathrm{Zn}$ and $\mathrm{Mg}$ anodes were used for the study. While, the concrete conductivity value and anode-cathode displacement did not change for each anode type, i.e. $0.007 \Omega-{ }^{1} \mathrm{~m}^{-1}$ and $20 \mathrm{~cm}$ respectively.

The BCs for rebar and $\mathrm{Zn}$ anode were the same with first simulation. While, for rebar and $\mathrm{Mg}$ anode, the $\mathrm{BCs}$ were generated from [20] as seen in Figure 4. In the simulation, the electrical potential value of Figure 3 and Figure 4 were already converted into a value referring to the $\mathrm{Cu} / \mathrm{CuSO}_{4}$ reference electrode.

\section{Results and discussion}

By using the $\mathrm{BC}$ as described in the previous section, BEM was executed in order to obtain electrical potential on the surface of rebar. Figure 5, Figure 6 and Figure 7 show the simulation results for the first simulation. The electrical potential distributions on the rebar surface are shown in the figures. For all figures, those show that the rebar part adjacent to the anode had a more negative electrical potential compared to the farthest part from the anode. This pattern was consistent with the previous research that conducted by Mahasiripan et al. [21] and Fonna et al. [10].

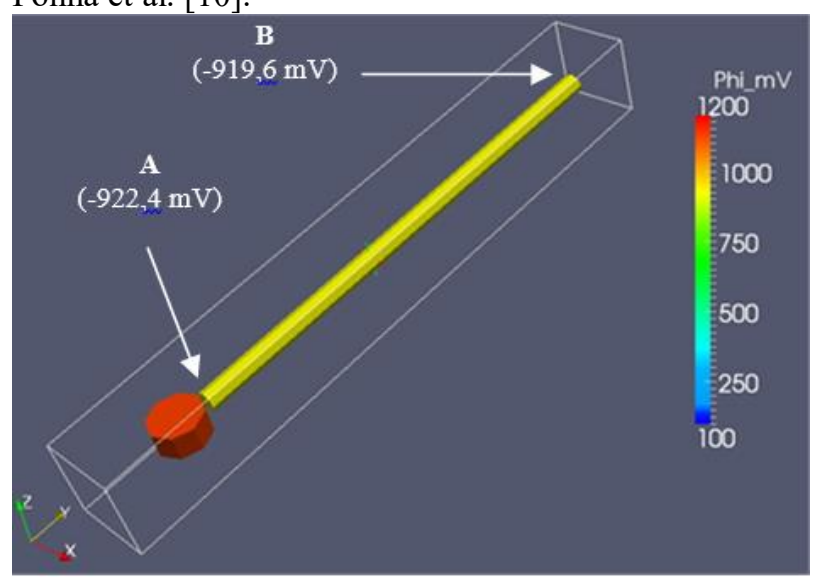

Fig. 5. Electrical potential distribution on rebar using $\mathrm{Zn}$ anode for $5 \mathrm{~cm}$ anode-cathode displacement.

Figure 5 shows the simulation result using $5 \mathrm{~cm}$ anode-cathode displacement. In the figure, it is seen that the distribution of electrical potential on the surface of the rebar is between -922.4 to $-919.6 \mathrm{mV}$. The most negative potential value is on the surface of rebar that closest to the sacrificial anode (point A).

Figures 6 and 8 show the distribution of electrical potential values on the surface of the rebar with anodecathode displacement 10 and $20 \mathrm{~cm}$. The potential distribution value for the $10 \mathrm{~cm}$ anode-cathode displacement is between -921.3 to $-919.6 \mathrm{mV}$. As for the $20 \mathrm{~cm}$ anode-cathode displacement is in the range -920.7 to $-919.6 \mathrm{mV}$. Both images also show that the most negative value is in the part of the nearest reinforcing steel from the sacrificial anode (point A).

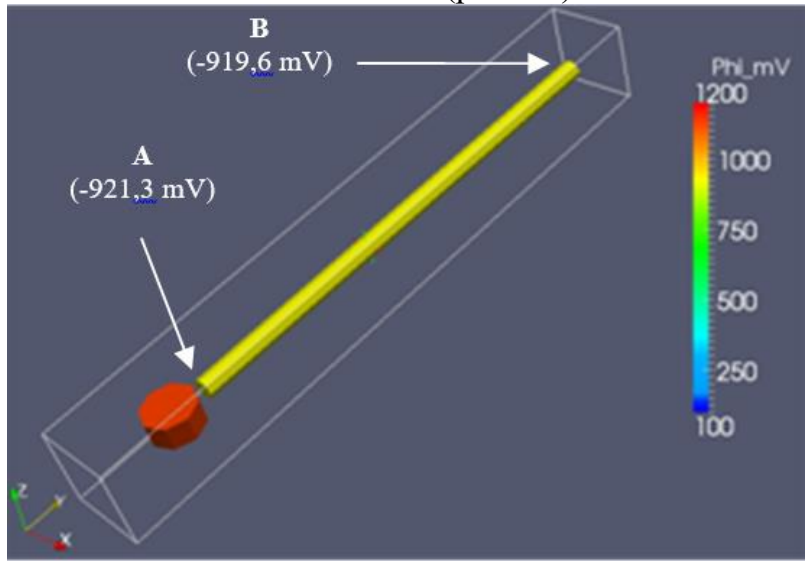

Fig. 6. Electrical potential distribution on rebar using $\mathrm{Zn}$ anode for $10 \mathrm{~cm}$ anode-cathode displacement.

Moreover, the effectiveness of the cathodic protection system in protecting corrosion can be evaluated from the electrical potential value with following existing standards and also the uniformly distributed potential value. The potential value of protection follows the NACE standard. Meanwhile, the uniform or uneven distribution of electrical potentials can be observed through the magnitude of the potential difference between the maximum and minimum potential values. The smaller difference in value, the electrical potential distribution becomes more evenly distributed.

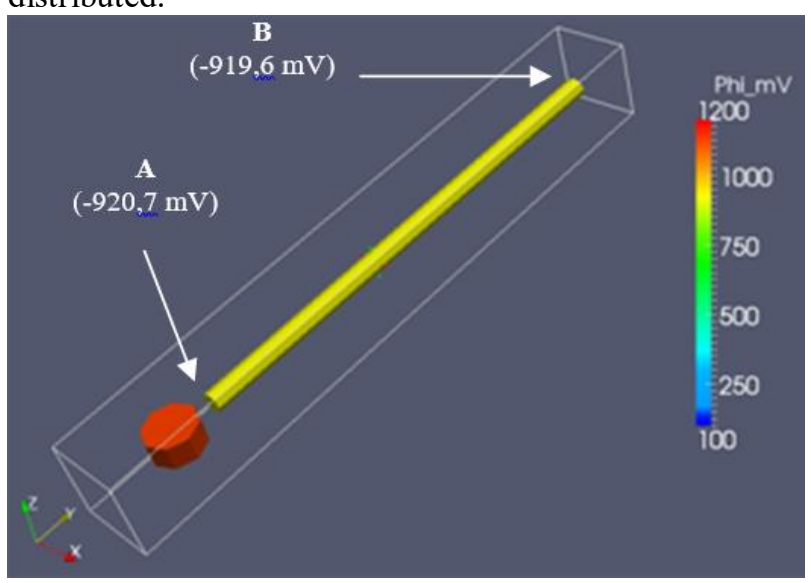

Fig. 7. Electrical potential distribution on rebar using $\mathrm{Zn}$ anode for $20 \mathrm{~cm}$ anode-cathode displacement.

In this study, the effect of anode-cathode displacement is analyzed based on the electrical potential difference value. The calculation results for the electrical potential differences were $2.8 \mathrm{mV}$ for the $5 \mathrm{~cm}$ anodecathode displacement; $1.7 \mathrm{mV}$ for the $10 \mathrm{~cm}$ anodecathode displacement; and $1.1 \mathrm{mV}$ for the $20 \mathrm{~cm}$ anodecathode displacement. The comparison between those results can be seen in Figure 8. 


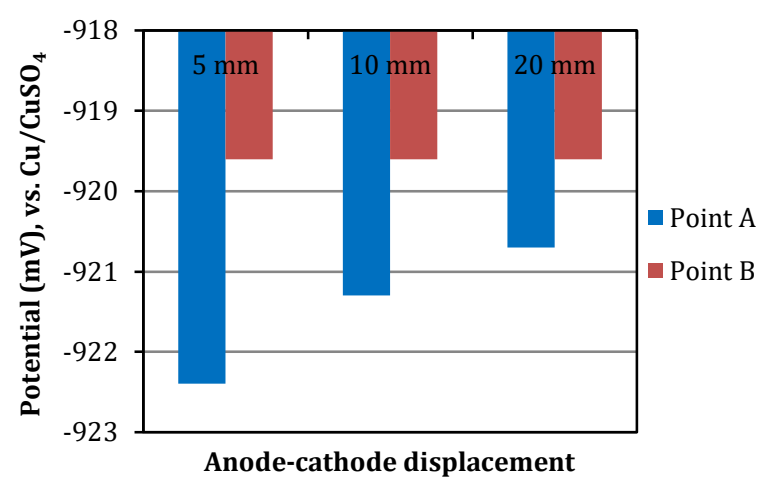

Fig. 8. The comparison of simulation results for different anode-cathode displacement.

Based on the electrical potential difference, it can be stated that the smaller the anode-cathode displacement might result in the uneven distribution of potential. Conversely, the greater the anode-cathode distance could result in a more equitable distribution of potential. However, it is estimated that there will be an optimum anode-cathode displacement that will provide a best potential distribution within the protection criterion. Thus, further research needs to be conducted to study the optimum anode-cathode displacement.

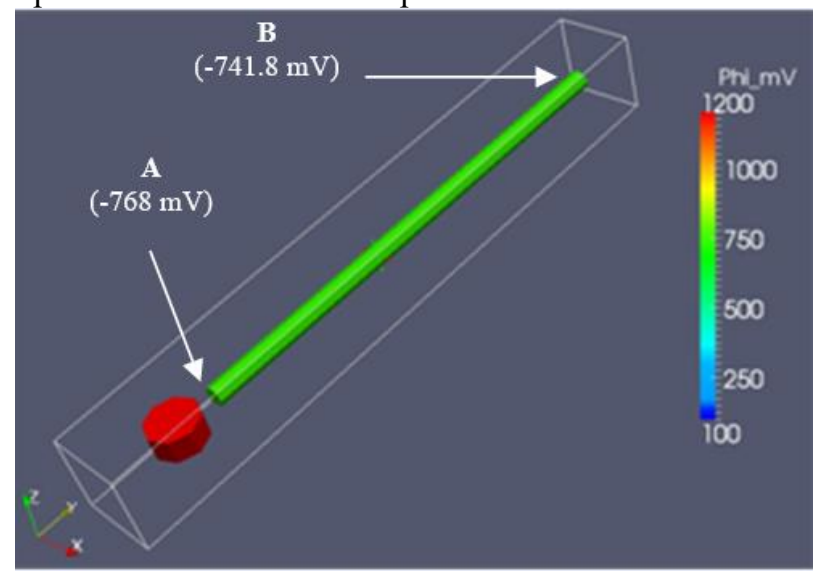

Fig. 9. Electrical potential distribution on rebar using $\mathrm{Mg}$ anode for $20 \mathrm{~cm}$ anode-cathode displacement.

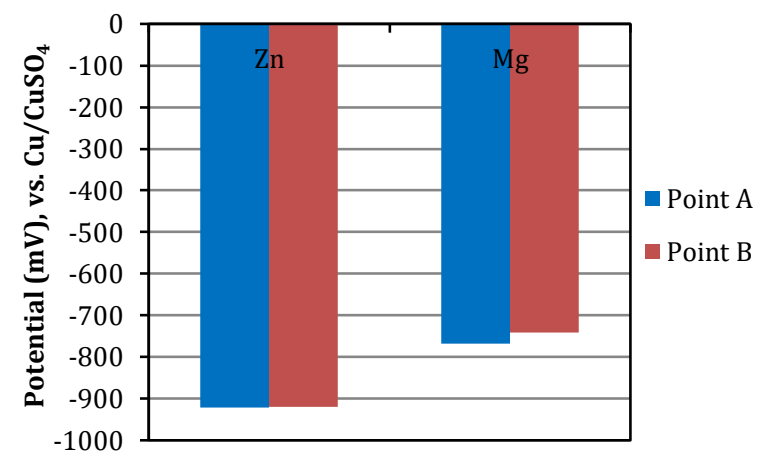

Fig. 10. The comparison of simulation results for different anode type.

The second simulation results using $\mathrm{Mg}$ anode is shown in Figure 9. While, using $\mathrm{Zn}$ anode is in Figure 7. In Figure 9, it can be seen that the electrical potential distribution on the surface of the rebar is between -768 to $-741.8 \mathrm{mV}$. Same as before, the most negative potential value is on the rebar that closest to the anode. Thus, it still consistent with the previous research result $[10,21]$.

The comparison of the electrical potential distribution between $\mathrm{Zn}$ anode and $\mathrm{Mg}$ anode is shown in Figure 10. The figure shows that $\mathrm{Zn}$ anode could provide more negative electrical potential than $\mathrm{Mg}$ anode. Hence, $\mathrm{Zn}$ anode might give more protection.

Therefore, simulation results show that the anode type, for sure, might affect the electrical potential distribution on the rebar. Hence, in designing and/or evaluating a cathodic protection system for $\mathrm{RC}$ structures, the effect of anode-cathode displacement and anode type need to be considered.

\section{Conclusions}

The simulation of the $\mathrm{CP}$ on an $\mathrm{RC}$ structure using the BEM was conducted in this study. From the results of the study, it can be concluded that:

- The anode-cathode displacement affects the electrical potential on the rebar.

- The electrical potential on the surface of the rebar might be affected by the anode type.

- It is important to consider those parameters in designing and/or evaluating the $\mathrm{CP}$ system for $\mathrm{RC}$ structures.

However, it is important to study on the optimum anode-cathode displacement for the CP system.

The research was supported by Penelitian Dasar Unggulan Perguruan Tinggi (PDUPT) No. 47/UN11.2/PP/SP3/2018, Ministry of Research, Technology and Higher Education, Indonesia. The development geometry and meshing used Salome software, while the visualization of the electrical potential data used Paraview software. Both are open source software.

\section{References}

1. NACE International, NACE study estimates global cost of corrosion at $\$ 2.5$ trillion annually https://inspectioneering.com/news/2016-0308/5202/nace-study-estimates-global-cost-ofcorrosion-at-25-trillion-ann (2016)

2. E.S. Cavaco, A. Bastos and F. Santos, Effects of corrosion on the behaviour of precast concrete floor systems, Construction and Building Materials 145, 411-418 (2017)

3. C. LeRose, The collapse of the Silver Bridge, West Virginia Historical Society Quarterly 15 (4), (2001)

4. CBC.ca, Former Quebec premier to head probe into overpass collapse, http://www.cbc.ca/news/canada/story/2006/10/02/la val-montreal.html (2006).

5. S. Fonna, M. Ridha, S. Huzni, W.A. Walid, T.D. Mulya T, and A.K. Ariffin, Corrosion risk of RC buildings after ten years the 2004 tsunami in Banda 
Aceh - Indonesia, Procedia Engineering 171, 965976 (2017)

6. S. Fonna, Gunawarman, S. Huzni, and A.K. Ariffin, Boundary element inverse analysis for rebar corrosion detection: Study on the 2004 tsunamiaffected structure in Aceh, Case Studies in Construction Materials 8, 292-298 (2018)

7. M. M. S. Cheung and C. Cao, Application of cathodic protection for controlling macrocell corrosion in chloride contaminated RC structures, Construction and Building Materials 45, 199-207 (2013)

8. G. Sergi, Ten-year results of galvanic sacrificial anodes in steel reinforced concrete, Materials and Corrosion 62, 98-104 (2011)

9. J. P. Broomfield, Corrosion of steel in concrete understanding, investigation and repair, 2nd ed., pp. 143-153, (Taylor \& Francis, London, 2007)

10. S. Fonna, S. Huzni, A. Zaim, and A.K. Ariffin, Simulation of Cathodic Protection on Reinforced Concrete Using BEM, J. of Mechanical Engineering (JMechE) SI4 (2), 111-122 (2017)

11. S. Aoki and K. Kishimoto, Application of BEM to galvanic corrosion and cathodic protection. Topics in Boundary Element Research 7, 65-86 (1990)

12. Safuadi, S. Fonna, M. Ridha, Zebua, A. K. Ariffin and A.R. Daud, Infinite boundary element formulation for the analysis of CP system for submersible pump, Applied Mechanics and Materials 471, 313-318 (2014)

13. Z. Lan, X. Wang, B. Hou, Z. Wang, J. Song and S.S. Chen, Simulation of sacrificial anode protection for steel platform using boundary element method, Engineering Analysis with Boundary Elements 36, 903-906 (2012)

14. M. Purcar, J. Deconinck, B. Van den Bossche, L. Bortels, Numerical 3D BEM simulation of a $\mathrm{CP}$ system for a buried tank influenced by a steel reinforced concrete foundation, WIT Transactions on Engineering Sciences 48, 47-56 (2005)

15. S. Fonna, S. Huzni, M. Ridha, and A.K. Ariffin, Inverse analysis using particle swarm optimization for detecting corrosion profile of rebar in concrete structure, Engineering Analysis with Boundary Elements 37 (3), 585-593 (2013)

16. S. Fonna, I. M. Ibrahim, M. Ridha, S. Huzni, and A.K. Ariffin, Simulation of the ill-posed problem of reinforced concrete corrosion detection using boundary element method, Int. J. of Corrosion 2016, $1-5$ (2016)

17. C. A. Brebbia and J. Dominguez, Boundary elements - an introductory course, 2nd ed., pp. 4770. (Computational Mechanic Publication/WIT Press, Southampton, 1998)

18. W. Dodds, C. Christodoulou, C.I. Goodier, and S.A. Austin, Performance Evaluation of Galvanic Anodes Through Laboratory Testing and On-Site Monitoring, RILEM International workshop on performance-based specification and control of concrete durability, 11 - 13 June, Zagreb, Croatia, 175-182. (2014)

19. R. G. Kasper, and M.G. April, Electrogalvanic Finite Element Analysis of Partially Protected Marine Structure, Corrosion, NACE International, 39 181-188. (1983)

20. J. X. Jia, G. Song and A. Atrens, Boundary element method predictions of the influence of the electrolyte on the galvanic corrosion of AZ91D coupled to steel, Materials and Corrosion 56 (4), 259-270 (2007)

21. A. Mahasiripan, S. Tangtermsirikul, and P. Sancharoen, A study of different sacrificial anode materials to protect corrosion of reinforcing steel in concrete, Thammasat Int. J. of Science and Technology 19 (4), 16-26 (2014) 